SPACECRAFT STANDARDIZA TION THROUGH NUCLEAR POWER

Elmer J. Frey, Bernard Raab, and Alfred Schock

Fairchild Space and Electronics Company, Germantown, Md.

Robert T. Carpenter

Space Nuclear Systems Division, United States Atomic Energy Commission, Germantown, Md.

\section{Abstract}

A conceptual design study showed that standardized, shuttle-launched spacecraft serving many space missions and a wide variety of orbital conditions could be designed around the use of nuclear electric power systems. One spacecraft design was based on the use of from one to three radioisotope thermoelectric generators (RTG) to provide up to 450 watts of electrical power. A second design based on a Brayton cycle alternator fueled by up to three of the same RTG heat sources meets power requirements from 500 to 2000 watts. Both spacecraft provide adequate weight, volume, and mounting surfaces for most of the payloads anticipated in the 1980 decade. A key to the broad applicability of the designs is the use of waste heat from the radioisotope heat sources to provide a benign environment for all internal equipment in all orbits with minimal spacecraft changes. Economic analysis indicated that the development cost of such spacecraft would be amortized over very few missions, with significant savings thereafter.

\section{Introduction}

This paper summarizes results of a study performed for the AEC/NASA Space Nuclear Systems Division in support of the ongoing NASA program aimed at reducing the cost of space missions.

In the design of space systems, weight and volume considerations have usually dictated that spacecraft be tailor-made to fit each mission. In these circumstances the power system with the lowest weight-per-watt or overall cost-per-watt is the logical choice. In most cases this has, quite properly, resulted in the selection of solar-array power systems for auxiliary power. Since the spacecraft is being specially designed to begin with, the special requirements of the solar-array system for the particular orbital conditions of the mission can usually be satisfied in the design.

With the advent of the Space Shuttle toward the end of this decade, however, changes in the groundrules will be inevitable. The large lifting capacity of this system $(65,000$ pounds in low earth orbit) and the substantially reduced cost of placing a pound of payload in orbit will obviate much of the incentive for speciallydesigned payload equipment to perform each mission. In addition, the mandated use of the Shuttle as a space ferry for all missions will strongly suggest the development of "standard spacecraft" with standard integration modes and procedures for use with this standard booster. These standard spacecraf $t$ should be capable of performing a variety of different missions without redesign or requalification. They would simply be outfitted with the specific equipment required for each mission. In concept, this equipment would only need to be integrated with the standard "housekeeping" systems provided by the standard spacecraft, such as telemetry, attitude control, and electrical power generation.

Under these groundrules, a nuclear system may be the more cost-effective choice for auxiliary power for most missions, even if the recurring cost of the generator itself were to remain relatively higher than that of a solar-array system of comparable capability. The fundamental advantage of the nuclear system in this context is that it provides power (and heat) which is not dependent on the sun-angle or occultation period, and is not degraded by trapped Van Allen or solar radiation. These highly orbit-dependent factors generally require solar-array systems to be specially designed for each mission. The use of solar arrays, in turn, tends to require the development of a customdesigned spacecraft for each mission, despite the relaxation of the weight and volume limitations permitted by the shuttle.

Nuclear systems, by contrast, are largely insensitive to orbital environmental factors. For example, the same basic nuclear generator (MHW-RTG) shown in Figure 1 is planned to be used in earth orbit (LES 8/9) and for deep-space missions (Mariner/Jupiter-Saturn). Moreover, the availability of solar-independent waste heat from the nuclear systems should permit the design of a thermal-control system which is largely orbit-and mission-independent, and which in turn permits the adaptation of various types of mission equipment without redesign of the standard spacecraft. This waste heat can be used to compensate for variations in solar input, earth reflection, and load power consumption, thus maintaining equipment temperature within acceptable limits for different orbits and mission-power profiles.

It is not suggested that solar-array power could not continue to be used for Shuttle-delivered missions; only that nuclear power readily lends itself to the design of multi-purpose spacecraft and can thereby result in significant cost benefits.

The study was focused on determining the feasibility of designing such a multiple-purpose spacecraft or family of spacecraft, examining its applicability to a wide variety of missions, and estimating the potential cost benefits.

\section{Conclusions}

The following are the fundamental conclusions * derived in the course of the study:

- Analysis of the most recent NASA mission model 


\section{DISCLAIMER}

This report was prepared as an account of work sponsored by an agency of the United States Government. Neither the United States Government nor any agency Thereof, nor any of their employees, makes any warranty, express or implied, or assumes any legal liability or responsibility for the accuracy, completeness, or usefulness of any information, apparatus, product, or process disclosed, or represents that its use would not infringe privately owned rights. Reference herein to any specific commercial product, process, or service by trade name, trademark, manufacturer, or otherwise does not necessarily constitute or imply its endorsement, recommendation, or favoring by the United States Government or any agency thereof. The views and opinions of authors expressed herein do not necessarily state or reflect those of the United States Government or any agency thereof. 


\section{DISCLAIMER}

Portions of this document may be illegible in electronic image products. Images are produced from the best available original document. 


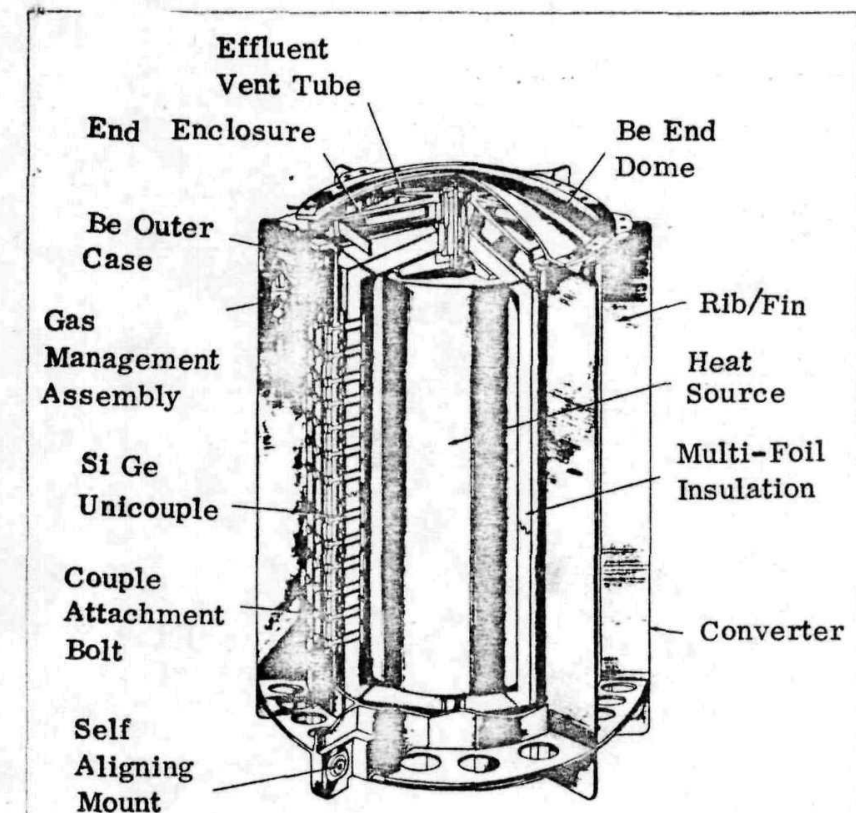

Fig. 1

150 Watt Radioisotope Thermoelectric Generator (RTG)

for the post-1979 time period revealed that many different missions can be divided into just a few groupings of common power, weight, and size.

- Two standard radioisotope-powered spacecraft, using present-day technology, can satisfy $80-90$ per cent of the unmanned earth-orbit missions listed in the NASA mission model for the 1979 - 1990 period. The spacecraft provide structure, thermal control, electrical power, attitude and velocity control (AVCS), and tracking, telemetry, and command (TTC) subsystems, The only missions excepted are those few which exceed either the weight-carrying capacity or the attitude control accuracy of the spacecraft as currently designed.

- Two nuclear power system designs, one for each spacecraft, can satisfy all the missions served. The systems are the Radioisotope Thermoelectric Generator (RTG) and the Radioisotope Brayton (RIB) system. For each spacecraft mission, power is provided as required in modular steps, either by addition of complete RTG's to provide power up to 450 watts(e) or by adding fuel capsules to the Brayton system to cover the range from 500 to 2000 watts(e). Both systems can use the same standardized heat source.

- Waste heat from the nuclear generators can be used to maintain spacecraft equipment temperatures within acceptable limits for all altitudes, sun angles, and equipment duty cycles. This is the key factor which permits standardization of the entire spacecraft despite the wide variety of mission conditions encountered.

- Savings of 64 percent for four missions using the standardized RTG spacecraft and 43 percent for six missions using the Brayton spacecraft, in comparison with mission-specialized solar-powered spacecraft, were estimated on the bas is of the cost model in the USAF Space Planners Guide. The calculations included both recurring and non-recurring costs, but excluded specialized payload equipment, launch, and operations costs. The savings over these missions, over and above those to be derived from the component and subsystem standardization program, are estimated to be 1.7 and 2.6 times the respective development cost of the standardized spacecraft. Thus the development cost can be amortized over relatively few missions and savings thereafter are appreciable.

\section{Functional Requirements and Mission Analysis}

A goal of the study is the conceptual design of nuclear-powered spacecraft capable of satisfying many different NASA missions without significant change in the standard spacecraft or their subsystems. The missions considered were those listed in the 1971 and 1972 NASA mission models (1), (2) with manned and interplanetary missions excluded by direction.

The mission models were reviewed to classify the demands made upon the various subsystems in order to furnish a basis for common designs. The analysis showed a high degree of commonality in functional demands, e.g. the greatest number of spacecraft are earth oriented, with a small number of observatories pointed toward the sun or other celestial objects. Three axis stabilization is required or desirable in most cases. Pointing accuracy of 0.1 degree satisfies the needs of most missions. Higher accuracy is ordinarily required only in knowledge of the orientation, and can be provided by the addition of appropriate sensing equipment and of ground data reduction as required. Telemetry, Tracking, and Command (TTC) requirements involve a fairly low data rate which fits within either VHF or $\mathrm{S}$ band and both are compatible with vehicle orientation and $w$ ith pointing accuracy requirements. High data rate payload communications could also be served if a tracking and data relay satellite system (TDRSS) becomes available. If a few specialized missions with very unusual parameters are removed from consideration, it becomes possible to satisfy most of the remaining missions with a limited number of choices corresponding to the mission parameters. The excluded missions were the large observatories, whose weight requirements substantially exceed those of all other missions, and certain physics experiments, such as a relativity experiment with extremely precise attitude control requirements. The large observatories could possibly be served by yet another standard spacecraft, but time did not permit such an investigation in this preliminary study.

The remaining missions, mostly earth observation, communications, and navigation, were then divided into two groups, depending on whether their electrie power requirements were more or less than 500 watts. This rather arbitrary division corresponds to the power ranges chosen for the RTG system (up to 450 watts) and for the Brayton system (above 500 watts). The study showed that, with two exceptions, the missions involving the lower power levels also involve spacecraft weighing less than 2000 pounds, while in general the missions requiring more than 500 watts involve weights above 2000 pounds. It was therefore decided 
that the entire range of requirements could conceivably be met by only two different spacecraft designs. This was subsequently verified by testing the designs against a number of specific missions with differing requirements.

Although the number of such test cases was necessarily limited, these were selected as representative of NASA missions with quite diverse requirements.

Clearly, the use of a multi-purpose spacecraft for most missions will result in many flights which do not appear "optimum" when viewed by current standards. For example, a spacecraft with a gross weight of 3000 pounds might be used to carry mission equipment which could conceivably fit within a 2000 pound spacecraft. At present, such poor design could result in millions of dollars of increased launch costs. In the Shuttle era, however, the cost of the "excess" weight could be entirely trivial, especially when compared to the potential cost benefits resulting from the elimination of the need to design, fabricate, and qualify an entirely new spacecraft for each mission.

Table 1 lists the design criteria which were applied to the standard spacecraft, based on the study of mission requirements.

Table 1 Standard Spacecraft Design Goals

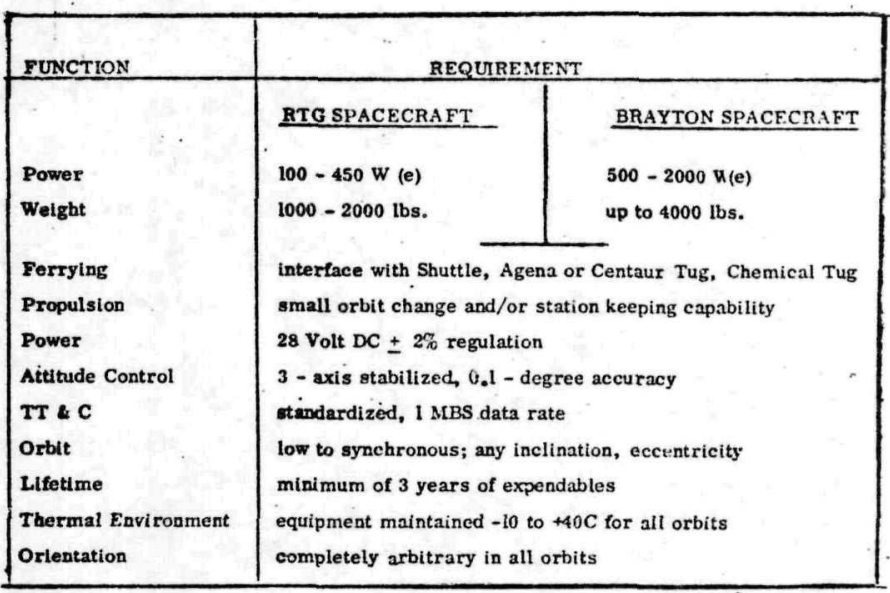

\section{Nuclear Power Systems}

The nuclear power systems postulated in the design study are the MHW-RTG ${ }^{(3)},(4),($ Fig. 1) and the Radioisotope Brayton (RIB) system (5). Both systems use the same standard heat source; the 2400 watt (thermal) Helipak heat source. This heat source, designed for service at $2000^{\circ} \mathrm{F}$, will be used at a maximum surface temperature of $1800^{\circ} \mathrm{F}$ in the RIB system.

Studies under NASA contract have shown that the same Brayton system can be used with high efficiency over a large range of output power by varying only the heat input and system gas pressure. This is a particularly useful characteristic where system weight is not of primary importance. An attractive option under these circumstances is to design the system for minimum weight at a relatively high power level; e.g., using three heat sources. This same system can then be used with either one or two heat sources with little or no loss in efficiency. In fact, w ith two heat sources, system efficiency is predicted to be somewhat higher because the oversized (for this case) radiator will reduce the compressor inlet temperature nearer to the optimum efficiency point. The nominal operating conditions are listed in Table 2 for the RTG and RIB systems.

Table 2. Power System Characteristics

\begin{tabular}{|c|c|c|c|c|}
\hline ARA & MHWw/ & & RIB & \\
\hline No. of Heat Sources & 1 & 1 & 2 & 3 \\
\hline Max. Power, BOL, w(e)* & 150 & 689 & 1588 & 2273 \\
\hline Net Conversion Efficiency, BOL, \% * & 6.25 & 28.7 & 33.1 & 31.6 \\
\hline Working Fluid Gas Flow Rate, $\cdot \mathrm{lb} / \mathrm{sec}$ & - & 0.1 & 0.2 & 0.3 \\
\hline System Total Weight, lb * & 85 & 651 & 696 & $7+1$ \\
\hline Output Voltage, vDC * & 30 & \multirow{5}{*}{\multicolumn{3}{|c|}{$\begin{array}{l}60 \text { depends on } \\
60 \text { packaging } \\
1600 \\
300-70\end{array}$}} \\
\hline Generator Envelope, length, in. & 21. & & & \\
\hline diameter, in. & 16 & & & \\
\hline Max. Cycle Temperature, ${ }^{\bullet} \mathbf{F}$ & 1800 & & & \\
\hline Nominal Radiator Temp. ${ }^{\circ} \mathrm{F}$ * & 550 & & & \\
\hline
\end{tabular}

- Values subject to modification by manner of integration of power system with spacecraft

\section{Space Shuttle System}

The assumed delivery vehicle is the shuttle orbiter, which has a cylindrical payload compartment 15 feet in diameter and 60 feet long. It is equipped with a remote manipulator system which can be used to handle payloads or to transfer fuel capsules, if this should ultimately prove to be desirable. The shuttle system can boost up to 65,000 pounds into a 100 nautical mile circular orbit $\left(28.5^{\circ}\right.$ inclination); 40,000 pounds into a polar $100 \mathrm{n}$. mi. orbit, or 50,000 pounds into a 270 n.mi. orbit at $28.5^{\circ}$. For normal boost periods, adequate heat storage is readily available in the shuttle to handle the waste heat from the radipisotope sources in the RTG Brayton systems. The doors of the payload bay would normally be opened after leaving the atmosphere, which permits direct radiation of the heat to space. Extended storage periods in the shuttle, particularly with bay doors closed, requires auxiliary heat storage or cooling, since the active temperature control system now planned for the shuttle payload compartment cannot handle the heat from the radioisotope sources.

\section{RTG Standard Spacecraft}

The standard RTG-powered spacecraft which evolved from the study, shown in Fig. 2, has the form 


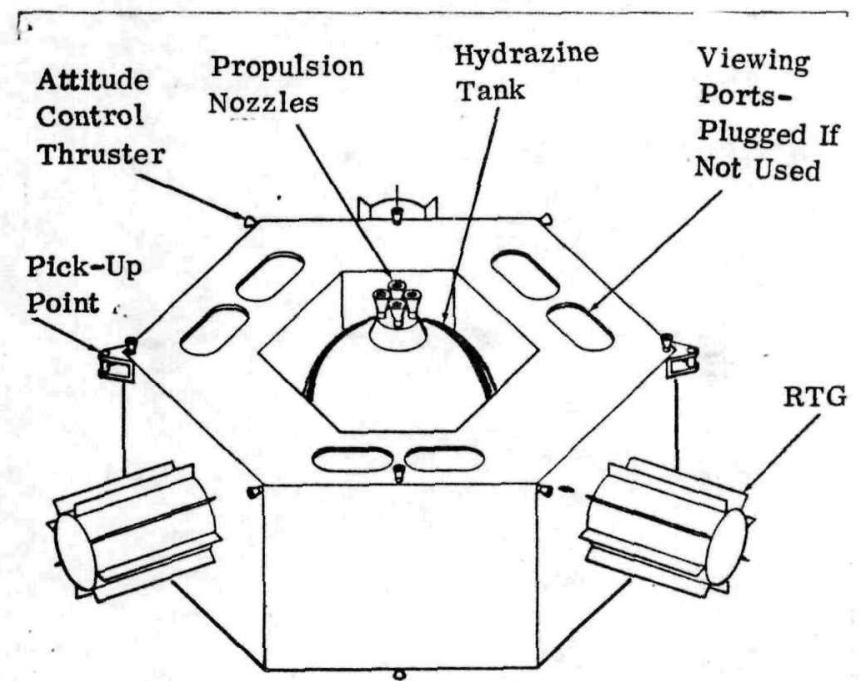

Fig. 2 Basic RTG Spacecraft-External View

of a hexagonal prism six feet across and three feet high. The space in the center is occupied by a hydrazine fuel tank and a set of thrusters used for orbit adjustment. Vehicle weight, including payload, can range from 1000 to 2000 pounds, depending on payload and power requirements.

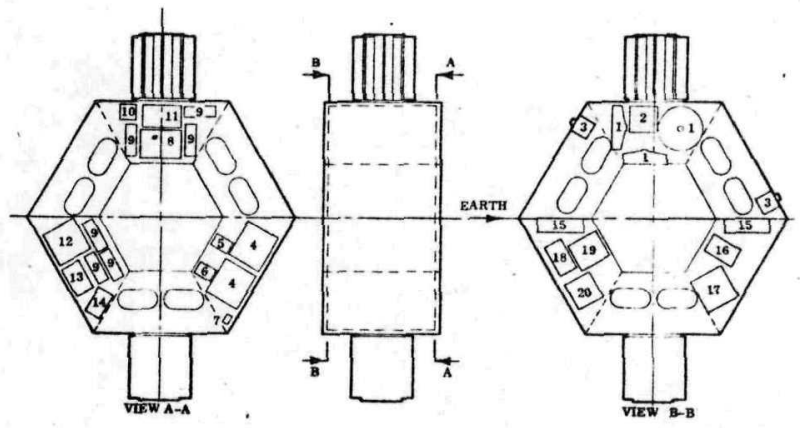

Fig. 3 Equipment Placement in RTG Spacecraft

Three compartments of the hexagonal prism contain the standard subsystems (Figure 3) and three compartments are available for payload. Viewing or communicating equipment requiring a clear field of view is mounted at one end of the prism; for example, in earthoriented missions, at that end which faces earth. Electronic and other temperature sensitive payload is mounted internally on the panels forming the two ends of the spacecraft. The faces have mounting holes and connectors for flexible payload placement. Large temperature-insensitive payload components, such as antennas, are mounted external to the spacecraft. Depending on the power level required, one, two, or three RTG units are mounted externally on the side faces of the prism, multiple units symmetrically and a single unit suitably counter-weighted. Access to internal equipment is through those side faces not bearing RTGs.
Table 3 Equipment List, Basic RTG Spacecraft

\begin{tabular}{|c|c|c|c|c|c|c|}
\hline ITEM & NAME & QTY. & \multicolumn{3}{|c|}{ SIZE } & WT. (EA.) \\
\hline 1 & REACTION WHEEL & 3 & 13.7 & DLA. & $\mathrm{X} 4.7$ & 19.7 \\
\hline 2 & EARTH SENSOR ELECT. & 1 & $8.5 \mathrm{X}$ & 8.0 & X 8.0 & 13.0 \\
\hline 3 & EARTH SENSOR & 2 & $5.5 \mathrm{x}$ & 5.5 & $\mathrm{x} 5.0$ & 1.0 \\
\hline 4 & COMPUTER & 2 & $12.0 \mathrm{X}$ & 11.0 & X 8.0 & 22.0 \\
\hline 5 & SUN SENSOR ELECT. & 1 & $4.0 \mathrm{X}$ & 5.75 & $\times 5.25$ & 3.0 \\
\hline 6 & RATE GYRO & 1 & $4.0 \mathrm{x}$ & 6.0 & $x 4.0$ & 4.0 \\
\hline 7 & SUN SENSOR & 2 & $1.0 \mathrm{X}$ & 2.0 & $\mathrm{X} 3.0$ & 1.0 \\
\hline 8 & ACTUATOR ELECT. & 1 & $9.0 \mathrm{X}$ & 12.5 & X 7.4 & 20.0 \\
\hline 9 & SHUNT & 6 & $3.5 \mathrm{x}$ & 10.0 & $\times 2.5$ & 2.3 \\
\hline 10 & LOAD CONTROLLER & 1 & $5.0 \mathrm{x}$ & 5.0 & $\times 5.0$ & 3.0 \\
\hline 11 & POWER CONDITION. & 1 & $6.0 \mathrm{x}$ & 8.0 & $\mathrm{X} 12.0$ & 17.6 \\
\hline 12 & VHF XMITTER & 1 & $11.0 \mathrm{X}$ & 11.0 & $x \quad 2.0$ & 4.0 \\
\hline 13 & LDR MULTIPLEXER & 1 & $6.0 \mathrm{x}$ & 10.0 & $\times 6.0$ & 6.0 \\
\hline 14 & BATTERY & 1 & $8.5 \mathrm{x}$ & 6.0 & $\mathrm{X} 11.5$ & 37.0 \\
\hline 15 & RECORDER & 2 & $15.0 \mathrm{X}$ & 4.5 & $\times 15.0$ & 20.0 \\
\hline 16 & MDR MULTIPLEXER & 1 & $6.0 \mathrm{X}$ & 610.0 & $x \quad 6.0$ & 6.0 \\
\hline 17 & S-BAND XMITTER & 1 & $11.0 \mathrm{x}$ & $\$ 11.0$ & $\times 2.0$ & 4.0 \\
\hline 18 & COMMAND DECODER & 1 & $6.0 \mathrm{X}$ & 10.0 & $\times 4.0$ & 5.0 \\
\hline 19 & VHF RECEIVER & 1 & $9.0 \times$ & 69.0 & $\times \quad 2.5$ & 6.0 \\
\hline 20 & S-BAND RECEIVER & 1 & $9.0 \mathrm{x}$ & 9.0 & $\times 2.5$ & 8.0 \\
\hline
\end{tabular}

Standard subsystems, listed in Table 3, include a 28 volt DC regulated $( \pm 2 \%$ ) power supply and a VHF and $\mathrm{S}$ band telemetry system with a $10^{6} \mathrm{bit} /$ second capacity. The hydrazine propulsion system has fuel capacity for at least a $1170 \mathrm{foot} /$ second velocity increment; because the thrusters are fixed, large increments will require spinning the vehicle. The configuration is chosen to facilitate balance and mass distribution suitable for stable spinning about the thrust axis. Small velocity increments, such as are applied in stationkeeping, do not require spinning; the attitude control system offsets any momentum due to misalignments of the central thrusters from the centroid of the vehicle. The three axis stabilization system employs reaction wheels and the hydrazine monopropellant thrusters for unloading the wheels, when necessary. Temperature of the hydrazine tank is suitably regulated by electric heaters.

The thermal control system provides a regulated environment between $-10^{\circ} \mathrm{C}$ and $+40^{\circ} \mathrm{C}$ for all spacecraft internal equipment in all conditions, i.e. regardless of occultations of the sun, aspect of the sun, earth albedo radiation and internally generated heat from spacecraft and mission equipment. This thermal independence of mission conditions makes it possible for the spacecraft to be used for a variety of missions. This is achieved by a thermal control system which uses part of the waste heat from the RTG units to overcome variations in heat originating from all other sources.

The case and fins on the RTG radiate most of the heat produced directly to space; their high temperature makes them effective radiators. Between the surface plate bearing the RTG and the rest of the spacecraft is a louver system which controls the rate at which heat is radiated from this plate to the other parts of the spacecraft. The movable vanes of the louver system automatically regulate the spacecraft temperature against variations due to changing heat inputs from other sources. The temperature of the spacecraft end panels is maintained relatively uniform by the use of heat pipes on the end faces of the prism. Standard emissivity coating and insulation techniques control the payload compartment temperature within the proper range despite differences in equipment power level and solar - and earth-originating radiation. 


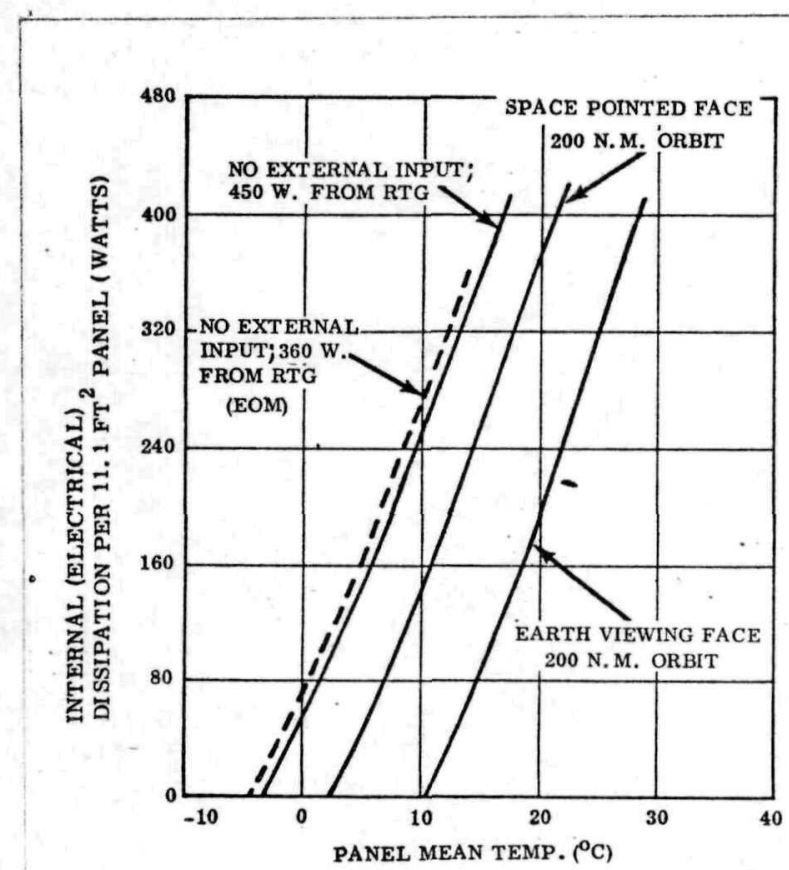

Fig. 4 Mounting Panel Temp. Range, RTG Spacecraft

Fig. 4 shows the effect of variations in power levels and mission conditions on the temperature of the end panels that support the equipment. These curves demonstrate the effectiveness of the system in providing a satisfactory environment in all conditions.

\section{Table 4 RTG Spacecraft Weight Estimates}

\begin{tabular}{|c|c|c|c|c|}
\hline \multirow{8}{*}{ 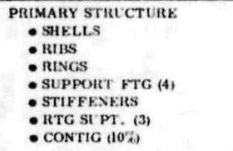 } & \multirow{8}{*}{ 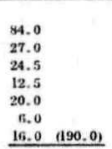 } & \multirow{2}{*}{\multicolumn{3}{|c|}{$\begin{array}{l}\text { ELECTRICAL POWER SYSTEM ICONTINUED } \\
\text { POWER CONDIT }\end{array}$}} \\
\hline & & & & \\
\hline & & - LOAD CONTROLLERR & 3.0 & \\
\hline & & - BatTERY cont. & 5.0 & \\
\hline & & - misc. & 5.0 & $(320.0)$ \\
\hline & & & & \\
\hline & & \multicolumn{3}{|l|}{ S/C PROPULSION AND ATTITUDE } \\
\hline & & CONTROL SYSTEM & & \\
\hline \multicolumn{2}{|l|}{ DQUTPMENT SLPPOIT STRUCTURE: } & LLANT & $\begin{array}{r}25.0 \\
372.0\end{array}$ & \\
\hline - ELECT. POWER & 3.0 & - SENSORS & 26.0 & \\
\hline & 7.0 & - WHEELS (3) & 58.0 & \\
\hline - TELE. \& COMMAND & 4.0 & - ELECtronics & 20,0 & \\
\hline - сомм. & 4.0 & - COMPUTERS & & $(546.0)$ \\
\hline - EXPERIMENTS & $7.0 \quad(25.0)$ & \multicolumn{3}{|l|}{ TELE. \& COMMAND SYSTEM } \\
\hline \multicolumn{2}{|l|}{ THERMAL CON } & \multirow{3}{*}{$\begin{array}{l}\text { - S BAND REC. } \\
\text { : S BAND TRAS. } \\
\text { - VHF REC. }\end{array}$} & 8.0 & \multirow{8}{*}{ on } \\
\hline - INSULA & 18.2 & & 4.0 & \\
\hline \multirow{5}{*}{$\begin{array}{l}\text { - HEAT PIPES } \\
\text { : VANES (3) } \\
\text { - RTG RADATORS (3) } \\
\text { - ISOLATOHS \& HEATERS }\end{array}$} & 2.5 & & 6.0 & \\
\hline & 31.0 & \multirow{2}{*}{$\begin{array}{l}\text { - VHF TRANS. } \\
\text { LDR MEX }\end{array}$} & 4.0 & \\
\hline & 6.9 & & 6.0 & \\
\hline & & \multirow{2}{*}{$\begin{array}{l}\text { - MDR MLX } \\
\text { - RECORDERS (2) }\end{array}$} & 6.0 & \\
\hline & $5.0 \quad(78,0)$ & & 40.0 & \\
\hline \multirow{2}{*}{\multicolumn{2}{|c|}{$\begin{array}{l}\text { ELECTRICAL POWER SYSTEM } \\
\text { - RTG (3) }\end{array}$}} & & & \\
\hline & & \multicolumn{2}{|l|}{ BASIC S/C WEIGHT } & (1236.0) \\
\hline \multirow{2}{*}{$\begin{array}{l}\text { - SHUNT REG. } \\
\text { FAULT DETECTOR } \\
\text { - SHUNT DISSIPATORS }\end{array}$} & $\begin{array}{r}37.0 \\
3.0\end{array}$ & MISSTON EQLTPMENT & - & $(764,0)$ \\
\hline & $\begin{array}{l}6.0 \\
3.4\end{array}$ & \multicolumn{2}{|l|}{ TOTAL S/C WEIGHT } & $(2000,0$ \\
\hline
\end{tabular}

Table 4 is a weight breakdown by subsystem of the maximum size 2000 pound RTG spacecraft carrying three RTG units. Note that this includes a large amount of propellant (370 lbs) for orbit adjustment purposes, and a battery in the electrical system to provide for periods of peak power exceeding the RTG capacity. Mission equipment weight allowance is 764 pounds.

Figures 5 and 6 show means of mounting the spacecraft within the orbiter vehicle, either directly to the attachment points in the payload compartment, or via a pallet capable of carrying both RTG and Brayton spacecraft individually or in combination. The pallet provides a versatile mounting structure which avoids placing bending moments on the orbiter vehicle.

Validity of the standard spacecraft concept was tested against the specific requirements of two different missions.

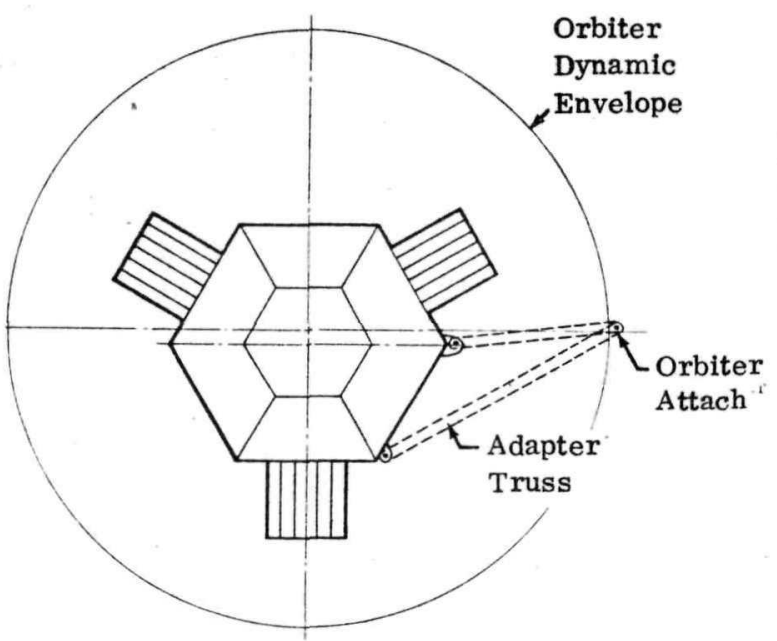

Fig. 5 RTG Spacecraft Mounting Direct to Orbiter

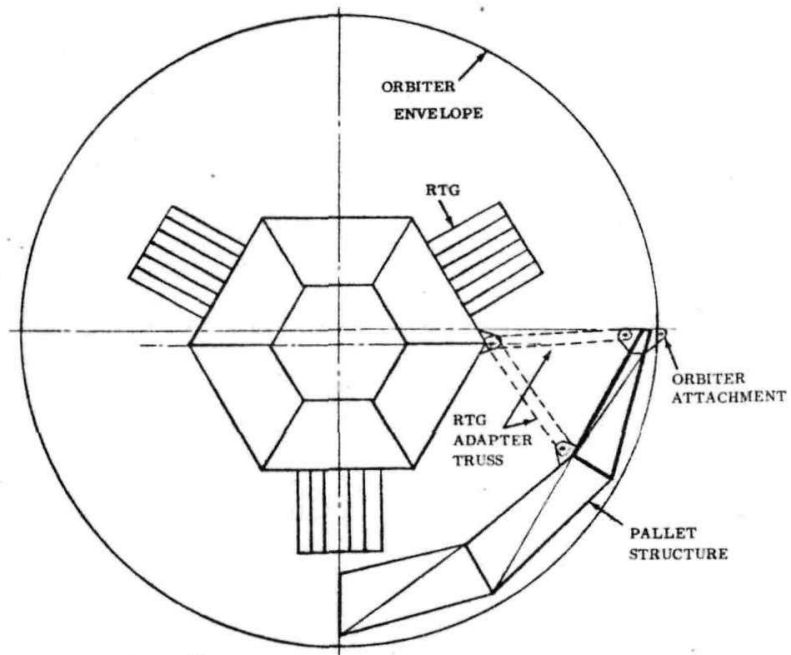

Fig. 6 RTG Spacecraft on Pallet in Orbiter

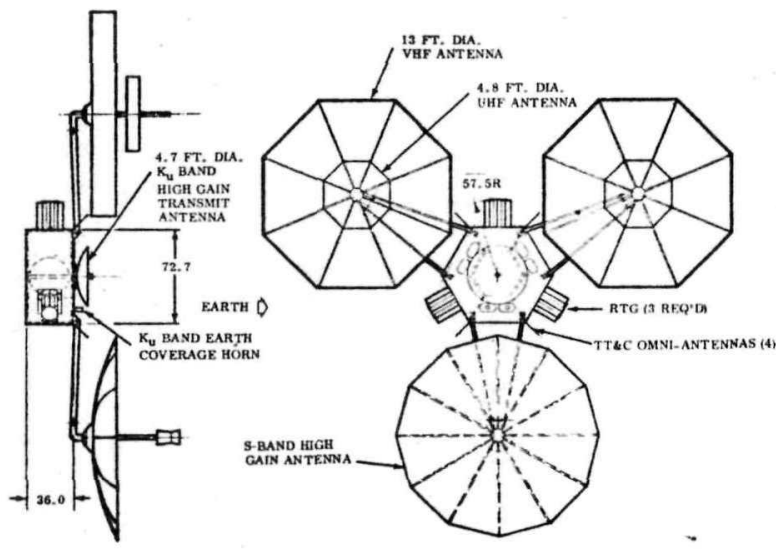

Fig.' 7

Tracking and Data Relay Satellite Equipment Deployed on RTG Spacecraft 
Figure 7 is a sketch of the spacecraft carrying the payload of the synchronous-orbit Tracking and Data Relay Satellite (TDRS), with the antennas deployed in operating configuration. Figure 8 is a layout of the same satellite in the stowed configuration used during transportation.
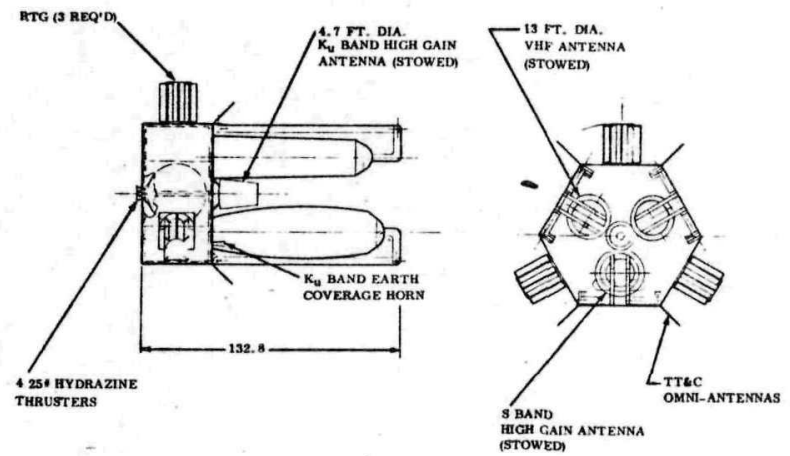

Fig. 8 TDRS Equipment on RTG Spacecraft Stowed Configuration

Fig. 9 is a sketch of the RTG bus bearing the payload proposed for the TIROS follow-on Meteorological Satellite. The standard spacecraft appears to be readily adaptable to both missions, although an economic analysis (Section 8) indicates that the former (TDRS) is performed at lower cost with the Brayton spacecraft described below.

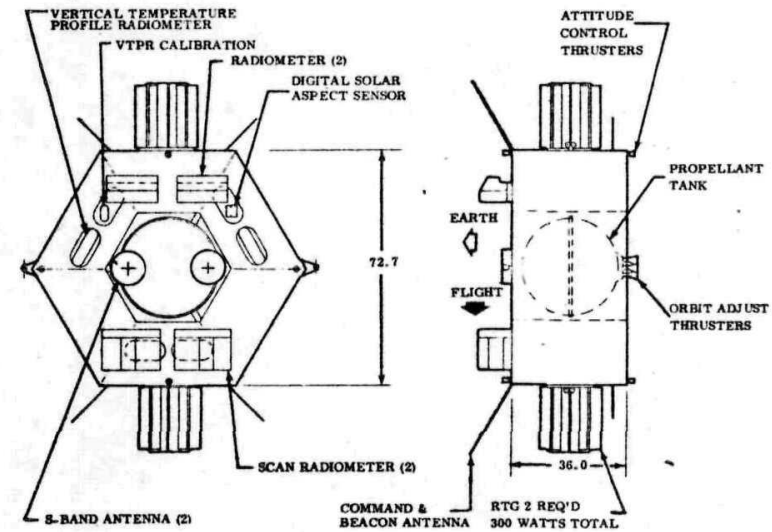

Fig. 9 Advanced TIROS Meteorological Satellite Payload on RTG Spacecraft

\section{The Brayton Standard Spacecraft}

Efficient operation of the Brayton electric system requires a relatively low compressor-inlet temperature and therefore a low radiator outlet temperature. This desired temperature is in the same range which is desirable for spacecraft equipment $(10-40 \mathrm{C})$. Consequently, the radiator was designed in the form of a uniform low-temperature shell forming the outer skin of the spacecraft and isolating it from varying solar and earth-originating thermal inputs. The dimensions of this shell are limited by the 15-foot diameter shuttle of the cargo bay. A diameter of 13 feet was eventually selected both for structural reasons, and in order to provide space for mounting to a supporting pallet for multiple payload launches or to a tug vehicle. To maintain a uniform thermal environment within the spacecraft shell an approximately isothermal radiator design was selected in preference to a more complex design, which would result from the use of a lighterweight, non-isothermal radiator.

Support of the structure and included payloads is provided by a four-foot diameter structural inner cylinder and interface ring. Figure 10 shows the spacecraft configuration as it eventually evolved. The outer shell does not bear primary loads and consequently is removable from the spacecraft for separate testing of the power plant prior to spacecraft assembly. The entire gas flow loop of the Brayton system was therefore designed to be integrally mounted to the outer shell. This permits testing of the power system separately from the spacecraft, and subsequent mating of the power system to the spacecraft late in the system assembly sequence.

Spacecraft and payload equipment can then be mounted on the two faces of the cylinder, readily accessible without penetrating the radiator shell, and with a clear view outward. Individual panels surrounding the inner structural ring provide mounting surfaces for the equipment, and are hinged to provide quick access. The radiator design temperature was selected to provide reasonable temperature regulation of the equipment in the face of thermal input perturbations (40C). With the completely enclosing radiator it was determined that no active temperature control is necessary if the radiator temperature is properly selected. In order to maintain this temperature with a different number of heat sources, a portion of the radiator must be thermally shielded from space when less than three heat sources are used.

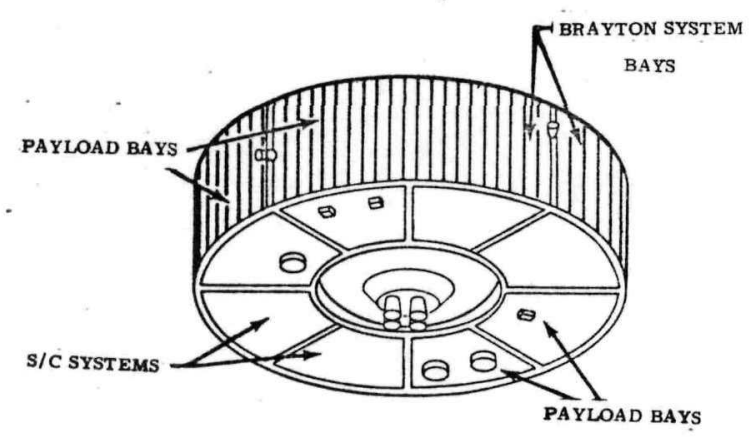

Fig. 10 Brayton Spacecraft

As with the RTG spacecraft, the central volume is occupied by a hydrazine tank and thrusters. Vehicle weight, including mission equipment, can range up to 4000 pounds. The spacecraft is divided into eight compartments, two occupied by the components of the Brayton power system, two by standard spacecraft 
subsystems, and four available for mission equipment (Fig. 11). For the earth-viewing missions, one end of the cylinder is pointed toward the target and directional equipment is mounted on this face. The two faces of the cylinder provide mounting surfaces for the spacecraft equipment and dissipate heat originating within the equipment. Temperature sensitive components are mounted inside the spacecraft; large temperature-insensitive components can be placed outside.

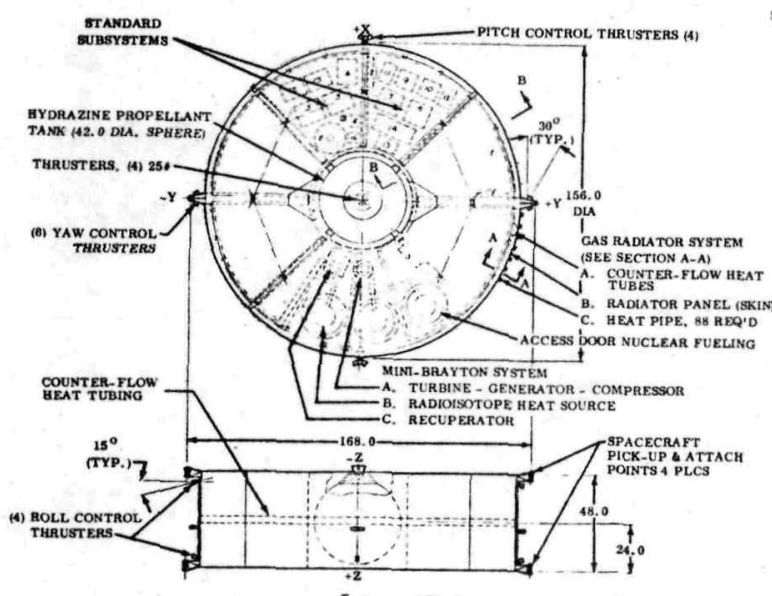

Fig. 11 Basic Brayton Spacecraft

Relatively uniform radiator temperature is achieved by dividing the Brayton working fluid into two streams which encircle the radiator in opposite directions. Figure 12 shows typical temperature profiles around the radiator circumference resulting from this counterflow arrangement. Heat is distributed over the entire radiator surface by axial heat pipes. The heat is radiated both outward to space and inward to the payload for thermal control.
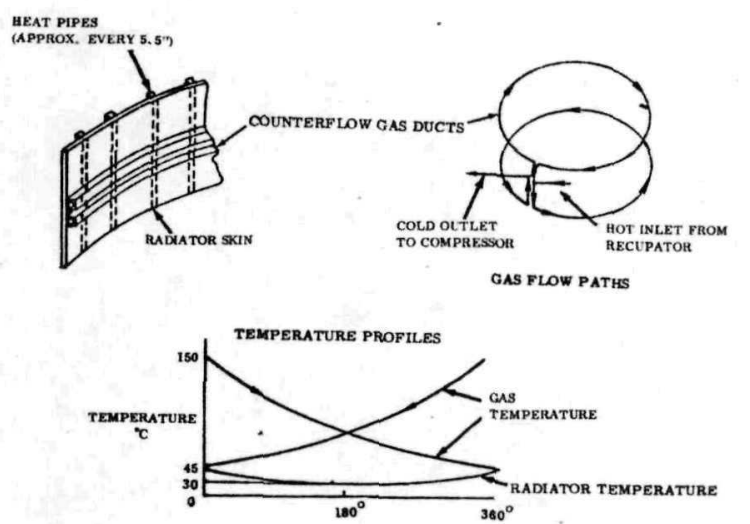

Fig. 12 Isothermal Radiator Configuration
The thermal control system differs from that of the RTG spacecraft in that heat input from the radiator is not varied with different conditions. However, it still provides environmental conditions between $-10^{\circ} \mathrm{C}$ and $+40^{\circ} \mathrm{C}$ for all spacecraft equipment in all conditions. Thus the Brayton satellite is adaptable to arbitrary earth-orbit mission conditions as required by the design goal.

Many subsystems, such as telemetry, propulsion and attitude control, are substantially identical to those of the RTG spacecraft except for size. The fixed-nozzle thrusters still require spinning the spacecraft to accomplish large velocity increments, and the configuration is arranged to give moments of inertia which provide stable spinning about the thrust axis. The AC power output of the Brayton alternator is converted to 28 volt $\mathrm{DC}$, regulated to $\pm 2 \%$. The power system provides parasitic loads to keep the Brayton unit operating at a constant speed of rotation despite variations in equipment load.

Table 5 is a weight breakdown for a 4000 pound spacecraft with three radioisotope fuel capsules and 560 pounds of propellant. The mission equipment allowance is almost 1900 pounds.

\section{Table 5 Brayton S/C Preliminary Weights}

\begin{tabular}{|c|c|c|}
\hline PRIMARY STRUCTURE & & ELECTRICAL PWR, SYS. (BRAYTON UNIT) \\
\hline & & (CONTINUED) \\
\hline - RIAS & 55.5 & - PLIMBINC \\
\hline & 83.5 & - electronics \\
\hline - STIFFENERS & 7.3 & - batt. \& INVERTer 59.0 \\
\hline - BRAYTON SPT. STR. & 18.0 & - PLR 20.0 \\
\hline - BUS SPT. STR. & 90.0 & $\begin{array}{ll}109.2 & (705.2) \\
\end{array}$ \\
\hline - CONTIG $(10 \%$ & $37.0 \quad(404.3)$ & \\
\hline & & 3/C PROPULSION AND ATTITUDE \\
\hline $\begin{array}{l}\text { EQUTPMENT SUPPORT STI } \\
\text { • ELECT. POWER }\end{array}$ & $\begin{array}{l}\text { RUCTERE } \\
5 .\end{array}$ & $\begin{array}{l}\text { CONTROL SYSTEM } \\
\text { • TANKS }\end{array}$ \\
\hline - SPS & 10. & - PROPELLANT \\
\hline - TELE. \& COMMAND & 5. & - SENSORS \\
\hline - сомм. & 5. & - WHEELS (3) \\
\hline - EXPERIMENTS & $(35.0)$ & - COMPUTERs $\{2\}$ \\
\hline & & - electronics \\
\hline $\begin{array}{l}\text { THERMAL CONTROL } \\
\text { • HEAT PIPES }\end{array}$ & & TELE, \& COMMAND SYSTEM \\
\hline - insulation & 35.0 & - S BAND REC. 8.0 \\
\hline - COATINGS & 17.0 & - $\mathrm{S}$ BAND TRANS. \\
\hline - PAINT & 5.7 & - VHF REC. \\
\hline - HeAters & 5.0 & - VHF TRANS. \\
\hline - MISC. isolators & $5.0 \quad(122.7)$ & - LDR MUX \\
\hline & & - MDR MLX \\
\hline ELECTRICAL PWR, SYS. & (BRAYTON UNIT) & - CMD DECODER \\
\hline $\begin{array}{l}\text { - GAS RADIATOR } \\
\text { HEAT SOURCES }\end{array}$ & 92.0 & - recorders (2) \\
\hline - REcUPERATOR & 68.0 & BASIC S/C WEIGHT \\
\hline - TURBINE & 25.0 & MISSION EQUIPMENT \\
\hline & & TOTAL SPACECRAFT \\
\hline
\end{tabular}

The adaptability of the standard Brayton spacecraft to two specific missions of diverse requirements was confirmed by detailed studies. Fig. 13 is a sketch of Earth Observation Satellite (EOS) equipment de-

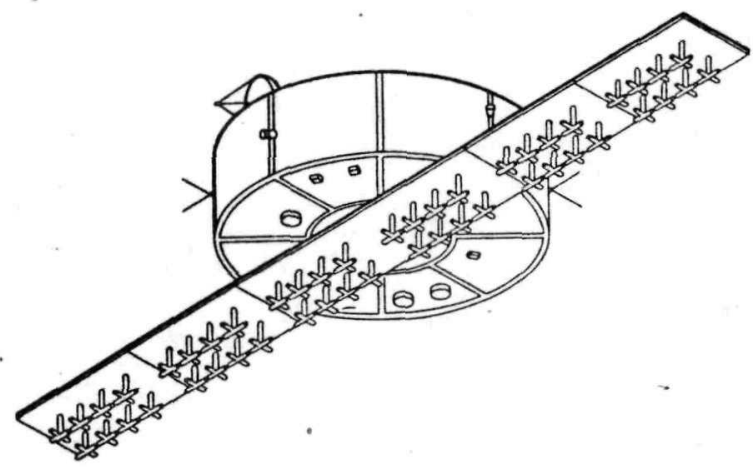

Fig. 13 EOS Equipment on Brayton Spacecraft 
Figures 14 and 15 show Applications Technology Satellite ATS-F equipment mounted on the spacecraft, in deployed and stowed configurations.

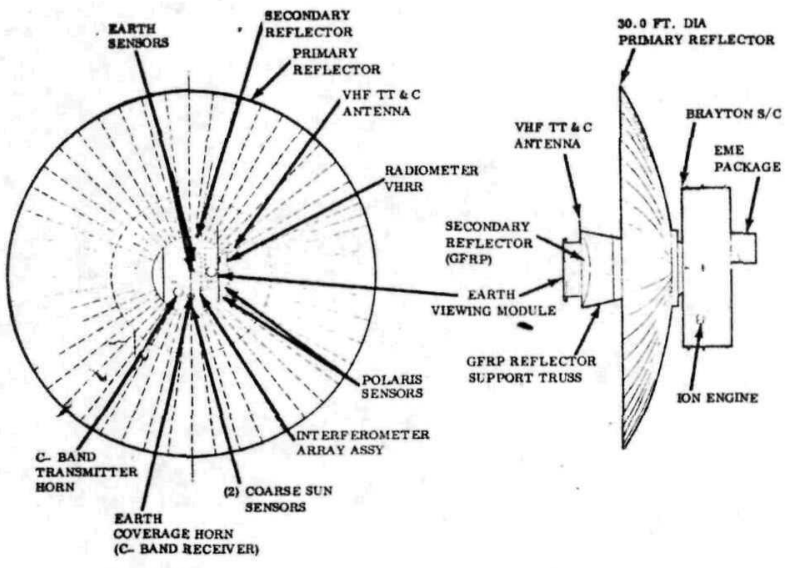

Fig. 14 ATS-F Equipment Deployed on Brayton Spacecraft

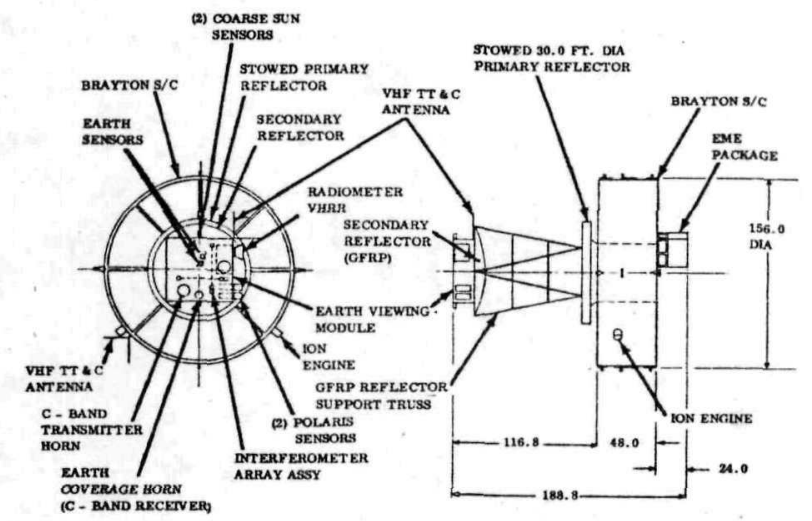

Fig. 15 A TS-F Equipment on Brayton Spacecraft Stowed Configuration

Fig. 16 shows both RTG and Brayton spacecraft on the same pallet within the orbiter.

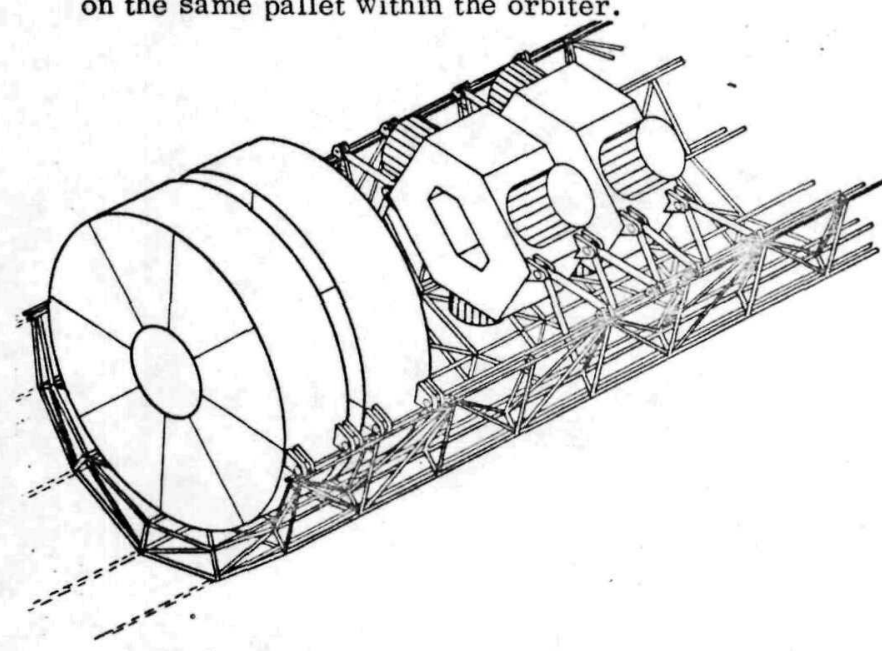

Fig. 16 RTG and Brayton Spacecraft Stacked on Pallet
VIII. Cost Analysis

Cost studies were carried out to compare standardized nuclear-powered spacecraft with mission-specialized (or "dedicated") solar-powered spacecraft. Attention was limited to ten missions from the NASA 1972 mission model which are now planned for the post 1979 period: five below 500 watts and five above 500 watts, i.e. in the RTG and Brayton system power ranges.

Launch costs, operational costs, and specialized mission equipment costs were not considered in this phase of the study. No detailed analysis was made for the cost increases for handling nuclear fuel, nor for reduction in launch and operational costs due to standardization. These two factors were assumed to offset each other. Mission equipment costs should be relatively unaffected by the nature of the spacecraft. In view of the relative imprecision of cost models, it was assumed that these particular costs are the same for both types of spacecraft, and attention was limited to the actual spacecraft costs and to the costs of the standard equipment provided for all missions.

The cost model was drawn from the section of the USAF Space Planners Guide dealing with space vehicle system costs. It divides the costs into non-recurring costs, involving development, test, and evaluation (DTE), facilities, and aerospace ground equipment (A GE), and recurring costs of production and operations. The operations costs are not included.

Within each category, costs are broken down by subsystems, and estimated from a set of curves which usually plot cost against weight. In most cases several different curves are furnished to cover different types of each particular subsystem. While the subsystem cost estimates may not be accurate, the total system costs do provide a reasonable reflection of existing system costs. The model is thus useful for quick estimates of total system costs during early stages of conceptual design.

Since the model was prepared in 1965 , costs were first increased by 30 percent to reflect inflation. The non-recurring DTE costs were then decreased by 25 percent to reflect the savings due to the NASA subsystem standardization program. The estimated weight of the dedicated spacecraft was assumed to be less than that of the standardized designs, since the former could presumably be more efficient in weight utilization by virtue of addressing only one mission rather than providing capability for a variety of missions. In the USAF cost models, this weight difference imposed a penalty on the standardized spacecraft, since all the spacecraft subsystem cost curves showed increasing cost with increasing weight.

Recurring costs were also estimated as a function of weight (or power, for the power subsystem only), with an initial unit cost modified by a set of "learning curves" to reflect the effects of the size of production runs. In general, the recurring costs for the standardized spacecraft are higher than those for the dedicated spacecraft, while the non-recurring costs are lower, since most of the DTE spacecraft costs were eliminated by the use of a standard design. 
TABLE 6

COST COMPARISON FOR FOUR LOW-POWER MISSTONS* STANDARDIZED RTG S/C VERSUS SPECIALIZED SOLAR-POWERED S/C in Millions of Dollars*"

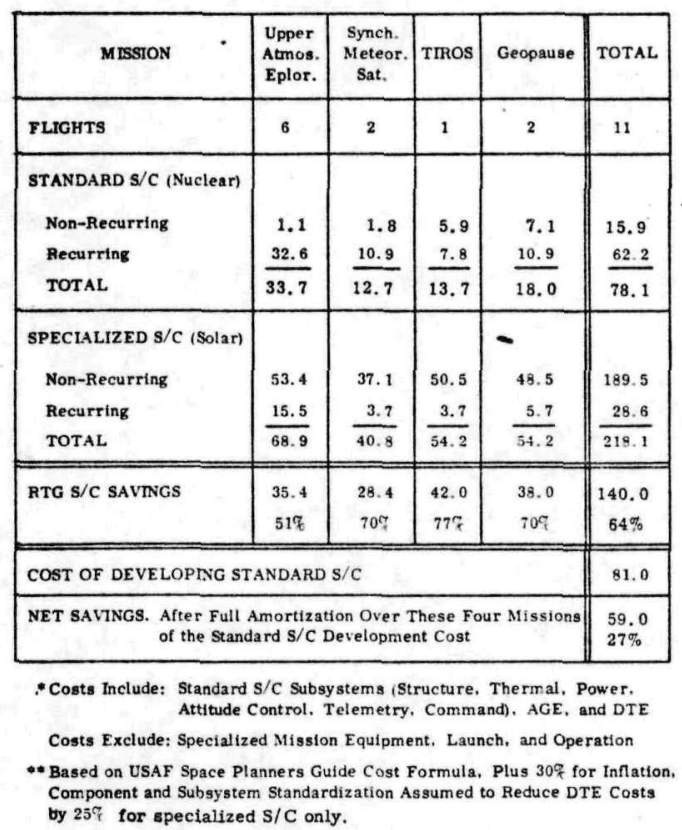

The comparison for four lower-powered missions serviced by the standard RTG spacecraft is shown in Table 6. The Tracking and Data Relay Satellite mission (TDRS), which required less than 500 watts, was found to be accomplished at lower cost by use of the Brayton bus. The table shows the pattern of higher recurring costs for the standardized spacecraft, and lower DTE costs. The final totals of $\$ 78$ million for the RTG spacecraft and $\$ 218$ million for the dedicated spacecraft show a savings of 64 percent from standardization. The total savings of $\$ 140$ million on these four missions more than amortize the estimated $\$ 81$ million cost of developing the standard RTG spacecraft.

Cost comparisons for six medium-power missions appear in Table 7, which estimates total costs for a Brayton-powered standard spacecraft and for a solarpowered dedicated spacecraft. This table shows overall costs of $\$ 358$ million for the standardized spacecraft and $\$ 636$ million for the dedicated spacecraft, or a net saving of 43 percent. The net savings of $\$ 295$ million completely amortize, over only a few missions, the $\$ 105$ million estimated cost of developing the Brayton spacecraft. The somewhat higher recurring costs of the standard spacecraft are more than offset by the savings in DTE. The non-recurring costs shown for the standard spacecraft consist principally of the cost of integrating each mission with the spacecraft.

More detailed cost studies using actual cost estimates instead of correlative models must await more detailed knowledge of the missions to be flown, and a clearer definition of shuttle utilization costs.

The net result of the cost studies is to show that standardized vehicles using nuclear power offer distinct savings over specialized solar-powered vehicles designed for each mission. In general, the fewer the number of flights in a given mission, the greater the percentage of savings provided by use of standardized spacecraft. The
TABLE 7

COST COMPARISON FOR SIX MEDIUM -POWER MISSIONS* GTANDARDIZED BRAYTON S/C VERSUS SPECLALIZED SOLAR-POWERED S/C In Millions of Dollars*"

\begin{tabular}{|c|c|c|c|c|c|c|c|}
\hline MISsION & EOS & sEOS & ERS & $\begin{array}{c}\text { Disaster } \\
\text { Warning } \\
\text { Satellite }\end{array}$ & $\begin{array}{c}\text { System } \\
\text { Test } \\
\text { Sat. }\end{array}$ & TDRS & TOTAL \\
\hline FLIGHTS & 7 & 5 & 8 & 2 & 8 & 6 & 36 \\
\hline \multicolumn{8}{|l|}{ STANDARD S/C (Nuclear) } \\
\hline Non-Recurring & 25.2 & 25.0 & 8.2 & 13.9 & 8.3 & 2.2 & 82.8 \\
\hline Recurring & 56.8 & 50.1 & 64.9 & 16.2 & 49.7 & 37.2 & 274.9 \\
\hline TOTAL & 82.0 & 75.1 & 73.1 & 30.1 & 58.0 & 39.4 & 357.7 \\
\hline \multicolumn{8}{|l|}{ SPECIALIZED S/C (Solar) } \\
\hline Non-Recurring & 79.5 & 78.7 & 79.4 & 74.3 & 103.8 & 38.4 & 454.1 \\
\hline Recurring & 37.7 & 25.5 & 43.1 & 11.0 & 54.4 & 10.7 & 192.4 \\
\hline TOTAL & 117.2 & 104.2 & 122.5 & 85.3 & 158.2 & 49.1 & 636.5 \\
\hline \multirow[t]{2}{*}{ BRAYTON S/C SAVINGS } & 53.8 & 3з. 9 & 37.5 & 62.6 & 97.4 & 9.7 & 274.8 \\
\hline & $46 \%$ & $33 \div$ & $31 \%$ & 737 & $61 \%$ & $20 \%$ & $43 \%$ \\
\hline \multicolumn{7}{|c|}{ COST OF DEVELOPING STANDARD S/C } & 105.0 \\
\hline \multicolumn{7}{|c|}{$\begin{array}{l}\text { NET SAVINGS. After Full Amortization Over These Six Missions } \\
\text { of the Standard S/C Development Cost }\end{array}$} & $\begin{array}{l}169.8 \\
27 \%\end{array}$ \\
\hline \multicolumn{8}{|c|}{$\begin{array}{l}\text { - Costs Include: Standard S/C Subsystems (Structure. Thermal. Power. } \\
\text { Attitude Control. Telemetry. Command). AGE. and DTE }\end{array}$} \\
\hline \multicolumn{8}{|c|}{ Costs Exclude: Specialized Mission Equipment. Launch. and Operation } \\
\hline \multicolumn{8}{|c|}{$\begin{array}{l}\text { ** Based on USAF Space Planners Guide Cost Formula, Plus } 30 \text {, for Inflation, } \\
\text { Component and Subsystem Standardization Assumed to Reduce DTE Costs } \\
\text { by } 25 \% \text { for specialized S/C only. }\end{array}$} \\
\hline
\end{tabular}

major saving occurs in the elimination of much of the expensive development, test, and evaluation which accompanies the use of specialized vehicles.

\section{REFERENCES}

(1) Aerospace Report A TR-72 (7231)-1, Vol. II (Aug. 1971), Integrated Operations/Payloads/Fleet Analysis Final Report.

(2) Aerospace Report A TR-72 (7312)-1, Vol. II (Aug. 1972):"NASA Payload Data Book, Payload Analysis for Space Shuttle".

(3) "Multi-Hundred Watt Radioisotope Thermoelectric Generator Program," General Electric Co. Report GESP-7071, GEMS-406, 1971.

(4) "Multi-Hundred Watt Radioisotope Thermoelectric Generator (MHW-RTG)," A.A. Pitrolo; R.B. Morrow; A.J. Arker, 1971 IECEC, Paper No. 719069.

(5) Isotope Brayton Electric Power System for the 500 to 2500 Watt Range, R.P. Macosko; G.J. Bama; H.B. Block; B.D. Ingle, 1972 IECEC Paper No. 729085 (also NASA TMX-68072). 


\title{
Spacecraft Standardization through Nuclear Power
}

\author{
Elmer J. Frey, ${ }^{*}$ Bernard RaAb, $\dagger$ and Alfred Schock $\ddagger$ \\ Fairchild Space and Electronics Company, Germantown, Md. \\ AND \\ ROBERT T. CARPENTER $\$$ \\ U.S. Atomic Energy Commission, Germantoun, Md.
}

\section{Theme}

A CONCEPTUAL design study showed that two standardized shuttle-launched spacecraft using nuclear electrical power could serve many missions in a wide variety of orbits. Development costs could be amortized over very few missions, with significant savings thereafter.

\section{Contents}

A study ${ }^{1,2}$ investigated whether the combination of the weight and volume capacity of the shuttle and the characteristics of nuclear electric power systems could make it possible to standardize spacecraft as well as subsystems. The standard spacecraft must provide space, mounting structure, environment and attitude control, power and telemetry for many missions with minimum changes and standard subsystems. Weight, volume, and thermal and solar array requirements (orbit-imposed) have usually led to custom design in the past. Nuclear systems provide power and heat independently of solar ocultation and aspect, and undegraded by Van Allen or solar radiation. The study examined feasibility of standard spacecraft design, applicability to specific missions, and costs.

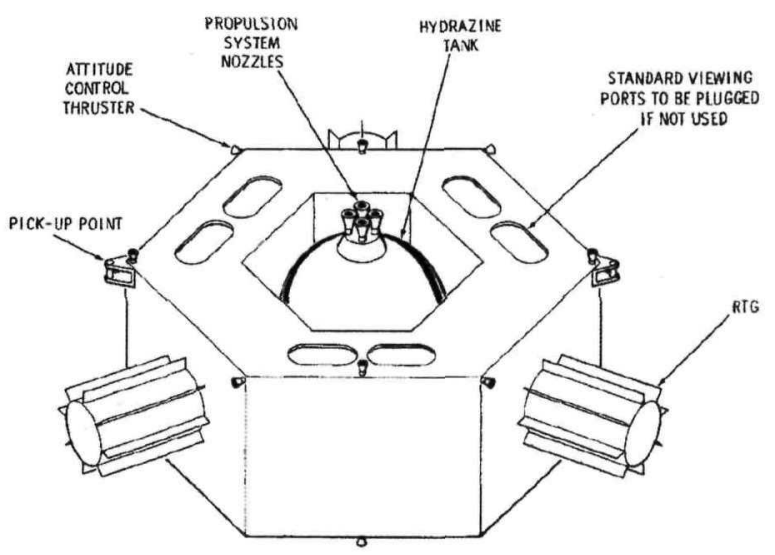

Fig. 1 Basic RTG spacecraft-external view.

Presented at the 8th Intersociety Energy Conversion Engineering Conference, Philadelphia, Pa., August 13-16, 1973; submitted November 9. 1973; synoptic received July 11, 1974. Full paper available from National Technical Information Service, Springfield, Va., 22151, as N74-31336 at the standard price (available upon request) This paper was based on work supported by the Atomic Energy Commission under Contract AT(49-15)-3063.

Index categories: Spacecraft Configurational and Structural Design (Including Loads); Spacecraft Electric Power Systems; Spacecraft

Mission Studies and Economics.

* Manager, Systems Analysis. Associate Fellow AIAA

+ Manager, Nuclear Applications. Member AIAA.

$\ddagger$ Manager, Nuclear Systems

$\S$ Assistant for Requirements and Applications, Space Nuclear Systems Division.
Table 1 Standard spacecraft design goals

\begin{tabular}{|c|c|}
\hline Function & Requirement \\
\hline & RTG spacecraft \\
\hline wer & $0-450 \mathrm{w}(\mathrm{e})$ \\
\hline & 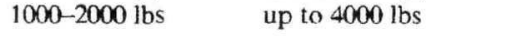 \\
\hline erry & \multirow{2}{*}{$\begin{array}{l}\text { interface with Shuttle, Agena or Centaur Tug. } \\
\text { Chemical Tug } \\
\text { small orbit change and/or stationkeeping } \\
\text { capability }\end{array}$} \\
\hline ropulsion & \\
\hline Power & $\begin{array}{l}28 \mathrm{v} \text { d.c. } \pm 2 \% \text { regulation, plus battery } \\
\text { capacity }\end{array}$ \\
\hline $\begin{array}{l}\text { Attitude cont } \\
\text { TT \& C }\end{array}$ & \multirow{2}{*}{$\begin{array}{l}\text { 3-axis stabilized, } 0.1^{\circ} \text { accuracy } \\
\text { standardized, } 1 \text { MBS data rate } \\
\text { low to synchronous; any inclination, ec- } \\
\text { centricity }\end{array}$} \\
\hline Orbit & \\
\hline Lifetir & \multirow{2}{*}{$\begin{array}{l}\text { minimum of } 3 \mathrm{yr} \text { of expendables } \\
\text { equipment maintained }-10 \text { to }+40 \mathrm{C} \text { for all } \\
\text { orbits }\end{array}$} \\
\hline it & \\
\hline Orientatio & completely arbitrary in all orbits \\
\hline
\end{tabular}

The classification of subsystem requirements (Table 1) as a basis of standardization resulted from analysis of the NASA unmanned mission model (interplanetary excluded). Correlation of size with power resulted in two groupings, with two satellite designs capable of serving most missions, except for a few special cases like the large observatories. Power levels from $150-450 \mathrm{w}$ are handled by a satellite with one to three radioisotope thermoelectric generators (RTG). The $500-2000 \mathrm{w}$ range is covered by a satellite with a Brayton cycle alternator fueled by from one to three of the same heat sources used in the RTG

Figure 1 shows the standard RTG spacecraft configurationa hexagonal prism with from one to three RTG units mounted externally on the side faces. Access to internal equipment is through the remaining sides. Top and bottom faces are used for mounting temperature sensitive items and for equipment needing an external field of view; large items can be mounted externally. Three sectors contain standard subsystems; three are available for payload. The center space can hold a hydrazine tank and fixed nozzle thrusters for orbit adjustments (1170 fps capacity); moments of inertia are suitable for spin stabilization during thrust. Total weight with payload can range from 1000$2000 \mathrm{lb}$.

Standard subsystems (about $300 \mathrm{lb}$, excluding the hydrazine and its tank) include a $28 \mathrm{v} \pm 2 \%$ power supply, some battery capacity, VHF and $S$-band telemetry of $1 \mathrm{Mbit} / \mathrm{sec}$ capacity, redundant central digital computers, and a three-axis stabilization system.

Average temperatures are adjusted to the mission by varying areas covered by emissivity coatings and insulation and by movable vane louvers which regulate the flow of waste heat from the RTGs to the satellite body to control temperature variations. Most of the RTG waste heat radiates directly to space from the high temperature case and fins. With heat pipes to keep them uniform in temperature the end panels remain 